\title{
Effects of Halogenation on Tyrosine Phosphorylation and Peptide Binding to the Src Homology 2 Domain of Lymphocyte-Specific Protein Tyrosine Kinase
}

\author{
Toshimitsu Okamura,* Tatsuya Kikuchi, Mika Nodaira, Kenichi Odaka, Kiyoshi Fukushi, and \\ Toshiaki Irie \\ Molecular Probe Program, Molecular Imaging Center, National Institute of Radiological Sciences; 4-9-1 Anagawa, \\ Inage-ku, Chiba 263-8555, Japan. \\ Received October 14, 2011; accepted December 8, 2011; published online December 15, 2011
}

Phosphorylation of tyrosine residues by protein tyrosine kinases (PTK) and phosphotyrosine/Src homology 2 (SH2) domain interactions are crucial not only for signal transduction but also for regulation of PTK activity. Tyrosine residues also receive nitration and halogenation under oxidative conditions. It has been reported that nitration of tyrosine residue caused peptides to be a poor substrate for PTK and that nitrotyrosine residues could bind to $\mathrm{SH} 2$ domains as a phosphotyrosine mimic to activate Src family kinase. However, the effect of halogenation on tyrosine phosphorylation or SH2 domain binding is not well understood. We examined the phosphorylation of model peptides containing 3-halotyrosine or 3-nitrotyrosine using typical receptor tyrosine kinase, epidermal growth factor receptor (EGFR), and nonreceptor tyrosine kinase, lymphocyte-specific protein tyrosine kinase (Lck). The EGFR- and Lck-mediated phosphorylation was markedly inhibited by tyrosine halogenation. Iodination showed the strongest inhibition of the phosphorylation among four types of halogenation, and its inhibitory effect was stronger than that of nitration. We also examined the effect of iodination and nitration of tyrosine residues on binding to the SH2 domain of Lck, using a model peptide containing the phosphoTyr-Glu-Glu-Ile motif, which has a high affinity for the SH2 domain. The relative affinities of the modified peptides whose phosphotyrosine was substituted with unphosphorylated tyrosine, 3-nitrotyrosine, and 3-iodotyrosine, and of the model peptide were $0.024,0.26$, 1 , and 16 , respectively. These results suggest that tyrosine iodination may have an effect on the phosphorylation or binding to the SH2 domain similar to nitration. Tyrosine iodination possibly modulates signal transduction, with the potential impairment of cell function.

Key words tyrosine halogenation; iodination; phosphorylation; Src homology 2 domain; kinase

Tyrosine phosphorylation is one of the key covalent modifications due to its capacity for transmitting biological information and for signal amplification. This modification is catalyzed by protein tyrosine kinases (PTK), which are categorized into two major groups: receptor tyrosine kinases (RTK) and nonreceptor tyrosine kinases (NRTK). Phosphorylation of tyrosine residues stimulates intrinsic kinase activity and produces recruitment sites for downstream signaling proteins containing phosphotyrosine-recognition domains, such as the Src homology 2 (SH2) domain. ${ }^{1)}$ These are crucial events in signaling pathways, the output of which ranges from cell division and migration (both associated with tumorigenesis) to adhesion, differentiation and apoptosis. ${ }^{2,3)}$

Tyrosine is also a target for protein oxidation and nitration, leading to the formation of halogenated tyrosine and nitrotyrosine by hypohalous acids and reactive nitrogen species (e.g. nitric oxide and peroxynitrite), respectively. ${ }^{4-6)}$ In human tissues, the halogenation and nitration of protein tyrosine residues have been demonstrated under physiological conditions and have been shown to increase significantly in inflammatory conditions and degenerative diseases. ${ }^{4,57)}$ Therefore these may be implicated in the onset or progression of certain disorders. Tyrosine nitration significantly modifies the functions of target proteins. For example, nitration of tyrosine residue severely impairs its capacity to serve as a substrate for PTK, which may downregulate phosphotyrosine-dependent signaling cascades. $^{8)}$ It has also been reported that nitrotyrosine residues can bind to $\mathrm{SH} 2$ domain as a phosphotyrosine mimic, to upregulate the activity of Src family kinases (SFKs). ${ }^{9)}$ While tyrosine nitration has been studied, few reports are available on the effect of halogenation on tyrosine phosphorylation and binding to $\mathrm{SH} 2$ domains.

In this study, we hypothesized that tyrosine halogenation may inhibit tyrosine phosphorylation and that halotyrosine residues can bind to $\mathrm{SH} 2$ domains, similarly to nitrotyrosine. We examined this hypothesis using model peptides containing 3-halotyrosine or 3-nitrotyrosine.

\section{MATERIALS AND METHODS}

Materials $\left[\gamma_{-}{ }^{32} \mathrm{P}\right] \mathrm{ATP}(\mathrm{ca} . \quad 3000 \mathrm{Ci} / \mathrm{mmol})$ was obtained from GE Healthcare UK Ltd. (Buckinghamshire, England). Resin and all necessary Fmoc-amino acids for peptide synthesis were obtained from Watanabe Chemical Industries, Ltd. (Hiroshima, Japan); 3-fluoro-L-tyrosine from Tokyo Chemical Industry Co., Ltd. (Tokyo, Japan); 3-chloro-L-tyrosine from Alfa Aesar $\mathrm{GmbH}$ and Co. KG (Karlsruhe, Germany); epidermal growth factor receptor (EGFR) and lymphocytespecific protein tyrosine kinase (Lck) from Upstate/Millipore (Billerica, MA, U.S.A.); Lck SH2 domain from Funakoshi Co., Ltd. (Tokyo, Japan). hmT peptides were purchased from Invitrogen Corporation (Carlsbad, CA, U.S.A.). Sensor Chip SA and HBS-EP buffer $(0.01 \mathrm{M} N$-(2-hydroxyethyl)piperazine$N^{\prime}$-2-ethanesulfonic acid, $0.15 \mathrm{M} \mathrm{NaCl}, 3 \mathrm{~mm}$ ethylenediaminetetraacetic acid (EDTA), 0.005\% Tween 20, pH 7.4) were obtained from Biacore (Uppsala, Sweden). Polyethyleneimine (PEI)-cellulose TLC sheets were purchased from Merck Ltd. (Tokyo, Japan). All other materials were obtained from a suit- 
able commercial source.

Peptide Abbreviations and Sequences The sequence of the PTK substrate peptide is H-Asp-Arg-Val-Tyr-Ile-His-ProPhe-OH (Angiotensin II, AII) in which the Tyr is intact and substituted with 3-fluoro-, 3-chloro-, 3-bromo-, 3-iodo-, or 3-nitro-tyrosine: AII-Y, AII-FY, AII-CIY, AII-BrY, AII-IY, and $\mathrm{AII}-\mathrm{NO}_{2} \mathrm{Y}$, respectively. Peptides used for the evaluation of binding to the $\mathrm{SH} 2$ domain are analogs of the peptide from hamster polyomavirus middle-sized tumor (hmT) antigen. The sequence of the peptide is Biotin-Ahx-Glu-Pro-Gln-TyrGlu-Glu-Ile-Pro-Ile-Tyr-Leu-OH in which the eighth Tyr from the C-terminal is intact, phosphorylated, and substituted with 3-iodo- or 3-nitro-tyrosine: hmT-Y, hmT-pY, hmT-IY, and hmT- $\mathrm{NO}_{2} \mathrm{Y}$, respectively.

Preparation of Peptide Substrates $N^{\alpha}$-Fmoc-Tyr(3-F)$\mathrm{OH}$ and $N^{\alpha}$-Fmoc-Tyr(3-Cl)-OH used for incorporation into the substrate peptide were synthesized essentially as described previously. ${ }^{10)}$ Briefly, Fmoc-Osu $(510 \mathrm{mg}, 1.5 \mathrm{mmol})$ in $1.2 \mathrm{~mL}$ of dimethylformamide (DMF) was added dropwise slowly to 3-fluoro- or 3-chloro-L-tyrosine $(150 \mathrm{mg}, 0.75$ or $0.70 \mathrm{mmol}$, respectively) in $1.5 \mathrm{~mL}$ of a mixture of $2 \mathrm{M} \mathrm{NaOH}$ aq in DMF $(1: 4)$ at $0^{\circ} \mathrm{C}$, and the $\mathrm{pH}$ adjusted to 9.0 with $5 \mathrm{~m} \mathrm{NaOH}$ aq. After $20 \mathrm{~h}$ of stirring with gradual warming to room temperature, the solution was poured into $30 \mathrm{~mL}$ of $5 \%$ citric acid and extracted with AcOEt ( $30 \mathrm{~mL}, 3$ times). The organic layer was washed with $100 \mathrm{~mL}$ of brine, dried $\left(\mathrm{Na}_{2} \mathrm{SO}_{4}\right)$, and evaporated. The residue was purified by silica gel column chromatography (Wakogel C-200) using hexane-AcOEt $(1: 1, \mathrm{v} / \mathrm{v})$ followed by hexane-AcOEt-AcOH $(8: 2: 0.1, \quad \mathrm{v} / \mathrm{v} / \mathrm{v})$, yielding $N^{\alpha}$-Fmoc$\operatorname{Tyr}(3-\mathrm{F})-\mathrm{OH}(>95 \%)$ or $N^{\alpha}-\mathrm{Fmoc}-\mathrm{Tyr}(3-\mathrm{Cl})-\mathrm{OH}(>95 \%)$ as an oil. ${ }^{1} \mathrm{H}-\mathrm{NMR}$ and FAB-MS data of these compounds are summarized in the supplementary data.

$N^{\alpha}$-Fmoc-Tyr(3-Br)-OH was synthesized as follows: $\mathrm{KBrO}_{3}$ (330 mg, $2.0 \mathrm{mmol})$ was added to Fmoc-Tyr-OH (800 mg, $2.0 \mathrm{mmol}$ ) in $38 \mathrm{~mL}$ of $\mathrm{AcOH}$-water $(5: 1)$, and then $40 \mathrm{~mL}$ of methanol was added to the mixture. The reaction mixture was refluxed at $80^{\circ} \mathrm{C}$ for $40 \mathrm{~min}$. After the evaporation of the solvent, the residue was dissolved in $30 \mathrm{~mL}$ of water and extracted with AcOEt $(30 \mathrm{~mL}, 3$ times). The organic layer was washed with $100 \mathrm{~mL}$ of brine, dried $\left(\mathrm{Na}_{2} \mathrm{SO}_{4}\right)$, and evaporated. The residue was purified by medium-pressure liquid chromatography (YAMAZEN Corporation, Osaka, Japan; silica gel $40 \mu \mathrm{m} \quad 60 \AA$; chloroform-methanol-AcOH, 10:0.2:0.1; $15 \mathrm{~mL} / \mathrm{min}$ ), yielding $N^{\alpha}$-Fmoc-Tyr(3-Br)-OH (43\%) as an oil. ${ }^{1} \mathrm{H}-\mathrm{NMR}$ and FAB-MS data of this compound are summarized in the supplementary data.

The AII peptides except for AII-Y (purchased from Wako Pure Chemical Industries, Ltd., Osaka, Japan) were synthesized according to the Fmoc solid-phase peptide synthesis protocol. ${ }^{11)}$ Following synthesis, the peptides were cleaved from the resin with trifluoroacetic acid (TFA)-water-triisopropylsilane $(95: 2.5: 2.5, \mathrm{v} / \mathrm{v} / \mathrm{v})$, precipitated and washed with diethyl ether, purified by HPLC, and lyophilized. The HPLC system consists of an L-7100 pump (Hitachi, Ltd., Tokyo, Japan), an L-7405 UV detector (Hitachi) set at $254 \mathrm{~nm}$, and a reverse-phase column (COSMOSIL 5C 18 -AR-300, 20 i.d. $\times 150 \mathrm{~mm}$, Nacalai Tesque, Kyoto, Japan). The column was eluted with acetonitrile containing $0.1 \%$ TFA-an aqueous solution of $0.1 \%$ TFA $(20: 80, \mathrm{v} / \mathrm{v})$ for $2 \mathrm{~min}$ at a flow rate of $5.0 \mathrm{~mL} / \mathrm{min}$, followed by a linear gradient of $20-50 \%$ acetonitrile over $58 \mathrm{~min}$. The peptides were analyzed by linear ion trap mass spectrometer (4000 Q TRAP LC/MS/MS System, Applied Biosystems, CA, U.S.A.). The purity of the peptides was $>98 \%$ as determined by analytical reverse-phase HPLC (COSMOSIL 5C 18 -AR-II, 4.6 i.d. $\times 250 \mathrm{~mm}$, Nacalai Tesque; acetonitrile containing $0.1 \% \mathrm{TFA} / \mathrm{an}$ aqueous solution of $0.1 \%$ TFA, $21: 79 ; 1.0 \mathrm{~mL} / \mathrm{min})$. Their MS data are summarized in the supplementary data.

Phosphorylation Level of the Modified AII Peptides by EGFR and Lck Phosphorylation levels were determined essentially according to the manufacturer's protocol (Upstate/ Millipore).

Phosphorylation by EGFR: $12.5 \mu \mathrm{L}$ of EGFR diluted with enzyme dilution buffer (20 mM 3-( $N$-morpholino)propanesulfonic acid (MOPS), pH 7.0, 1 mм EDTA, 0.01\% Brij-35, 5\% glycerol, $0.1 \%$ 2-mercaptoethanol, $1 \mathrm{mg} / \mathrm{mL}$ bovine serum albumin) was added to $62.5 \mu \mathrm{L}$ of mixture containing $25 \mu \mathrm{L}$ of reaction buffer ( $40 \mathrm{~mm}$ MOPS, $\mathrm{pH} 7.0,1 \mathrm{~mm}$ EDTA), $25 \mu \mathrm{L}$ of $4 \mathrm{M}$ ammonium sulfate, $6.25 \mu \mathrm{L}$ of $200 \mathrm{~mm} \mathrm{MnCl}_{2}$, and $6.25 \mu \mathrm{L}$ of $10 \mathrm{~mm}$ modified AII peptide. The reaction mixture was preincubated for $5 \mathrm{~min}$ at $30^{\circ} \mathrm{C}$, and then $50 \mu \mathrm{L}$ of $\left[\gamma_{-}{ }^{32} \mathrm{P}\right] \mathrm{ATP}$ solution $(400-800 \mathrm{cpm} / \mathrm{pmol})$ was added to initiate the reaction. The final ATP concentration was $100 \mu \mathrm{M}$. At designated time points, the reaction was terminated by the addition of $25 \mu \mathrm{L}$ of the reaction mixture to $10 \mu \mathrm{L}$ of $10 \%$ trichloroacetic acid. The resultant solution $(2 \mu \mathrm{L})$ was applied to PEI-cellulose TLC sheets, and developed with isobutyric acid-water-25\% aqueous ammonia $(66: 33: 1, \mathrm{v} / \mathrm{v} / \mathrm{v})$. The air-dried TLC sheet was covered with a thin plastic film (lumilar film) and placed in a cassette in contact with an imaging phosphor plate for several hours. Radioactivity of phosphorylated peptides on TLC was quantified using the BAS 1800 System (Fuji Photo Film Co., Ltd., Tokyo, Japan). Determinations were made in triplicate.

Phosphorylation by Lck: $2.5 \mu \mathrm{L}$ of Lck diluted in enzyme dilution buffer was added to $12.5 \mu \mathrm{L}$ of solution containing $6.25 \mu \mathrm{L}$ of reaction buffer $(200 \mathrm{~mm}$ Tris $-\mathrm{HCl}, \mathrm{pH} 7.5,0.4 \mathrm{~mm}$ EDTA, $0.4 \mathrm{~mm} \mathrm{Na}_{3} \mathrm{VO}_{4}$ ), $2.5 \mu \mathrm{L}$ of $2.5 \mathrm{~mm}$ modified AII peptide, and $3.75 \mu \mathrm{L}$ of distilled water. After preincubation for $5 \mathrm{~min}$ at $30^{\circ} \mathrm{C}$, the reaction was initiated by the addition of $10 \mu \mathrm{L}$ of $\left[\gamma_{-}{ }^{32} \mathrm{P}\right]$ ATP solution $(400-800 \mathrm{cpm} / \mathrm{pmol})$. At designated time points, the reaction was terminated by the addition of $3 \mu \mathrm{L}$ of reaction mixture to $27 \mu \mathrm{L}$ of $3 \%$ phosphoric acid. The resultant solution was analyzed by PEI-cellulose TLC as described above. Determinations were made in triplicate.

Images of radioactivity on TLC sheets and identification of phosphorylated peptides by mass spectrometry are shown in the supplementary data.

Binding Affinity of hmT Peptides to the Lck SH2 Domain Binding experiments were performed on the BIAcore 2000 instrument (Biacore, Uppsala, Sweden). The peptides used in this experiment were analogs of hmT-pY that contains the pTyr-Glu-Glu-Ile motif and can bind the SH2 domain of SFKs with high affinity. ${ }^{12,13)}$ The hmT peptides were immobilized on a streptavidin-conjugated sensor chip (Sensor Chip SA), according to the manufacturer's instructions. Lck SH2 domain in HBS-EP buffer at various concentrations was injected into the hmT peptide-immobilized flow cell with a flow rate of $20 \mu \mathrm{L} / \mathrm{min}$ at $25^{\circ} \mathrm{C}$. Both the association and dissociation phases were followed for $2 \mathrm{~min}$. After each run, $10 \mathrm{~mm}$ Glysine- $\mathrm{HCl}(\mathrm{pH} 2.0)$ was injected twice to regenerate the hmT peptide-immobilized surfaces at $20 \mu \mathrm{L} / \mathrm{min}$ for $1 \mathrm{~min}$. A dissociation constant $\left(K_{\mathrm{D}}\right)$ was determined by a nonlinear 

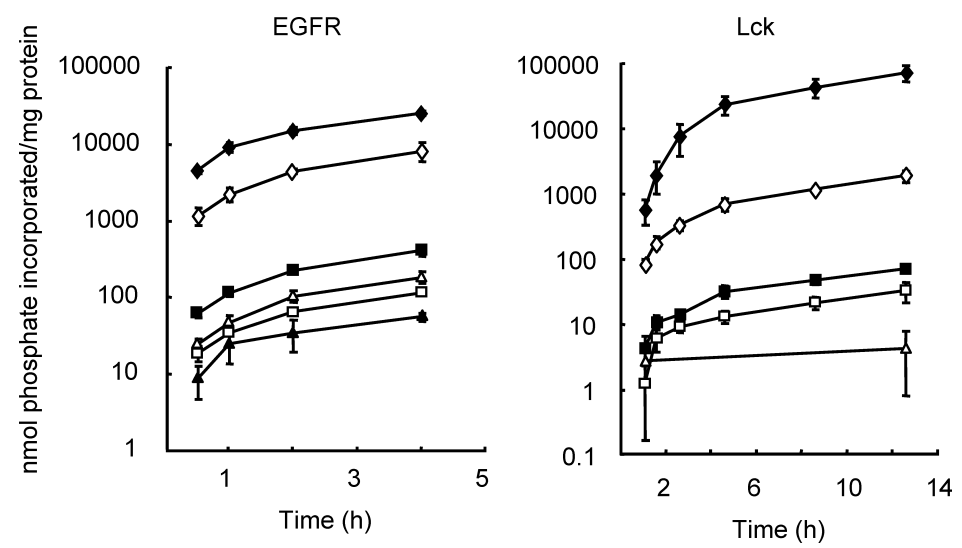

Fig. 1. The Phosphorylation Level of AII-Y (Filled Diamond), AII-FY (Open Diamond), AII-ClY (Filled Square), AII-BrY (Open Square), AII-IY (Filled Triangle), and AII-NO 2 Y (Open Triangle) by EGFR and Lck

Lck-dependent phosphorylation of AII-IY could not be detected even $12 \mathrm{~h}$ after incubation. Data are given as mean \pm standard deviation $(n=3)$.

fitting method, using BIAevaluation version 3.1 software (Biacore).

\section{RESULTS}

Phosphorylation Level of the Modified AII Peptides by EGFR and Lck To evaluate the effect of tyrosine halogenation on phosphorylation by PTK, the phosphorylation level of the modified AII peptides was determined following treatment with EGFR or Lck, typical RTK or NRTK, respectively. As shown in Fig. 1, tyrosine halogenation of AII caused the inhibition of phosphorylation by EGFR and Lck. Phosphorylation following EGFR treatment was AII$\mathrm{Y}>\mathrm{AII}-\mathrm{FY}>\mathrm{AII}-\mathrm{ClY}>\mathrm{AII}-\mathrm{NO}_{2} \mathrm{Y}>\mathrm{AII}-\mathrm{BrY}>\mathrm{AII}-\mathrm{IY}$; following Lck treatment was AII-Y $>$ AII-FY $>$ AII-ClY $>$ AII-BrY $>$ AII$\mathrm{NO}_{2} \mathrm{Y} \gg$ AII-IY. Thus, iodination showed the strongest inhibition of phosphorylation among the four types of halogenation, and its inhibitory effect surpassed that of nitration.

Binding Affinity of hmT Peptides to the Lck SH2 Domain We examined how iodination and nitration of tyrosine residues affected binding to the $\mathrm{SH} 2$ domain of Lck. The dissociation constants $\left(K_{\mathrm{D}}\right)$ of the hmT peptides to Lck $\mathrm{SH} 2$ domain are shown in Table 1. The rank order of binding affinity was hmT-pY $>$ hmT-IY $>$ hmT-NO 2 Y $>$ hmT-Y. The peptides hmT-IY and hmT-NO $\mathrm{N}_{2} \mathrm{Y}$ have the ability to bind to Lck $\mathrm{SH} 2$ domain without phosphorylation, although their affinities were much lower than that of hmT-pY. The hmT-IY peptide bound to the SH2 domain with four times higher affinity than hmT-NO $\mathrm{N}_{2} \mathrm{Y}$.

\section{DISCUSSION}

Tyrosine phosphorylation of proteins or enzymes by PTK is an important cellular regulatory mechanism, especially in signaling transduction pathways, including cell proliferation, differentiation, and apoptosis. Previous in vitro studies showed that nitration of tyrosine residues prevented tyrosine phosphorylation, which would affect various cell functions. ${ }^{8,14}$ Similarly to tyrosine nitration, halogenation of tyrosine residues is expected to inhibit tyrosine phosphorylation. Indeed, such inhibition was observed although there was a difference in the degree of inhibition of tyrosine phosphorylation among the four types of halogenation. The inhibitory effect
Table 1. Dissociation Constants of the hmT Peptides to Lck SH2 Domain

\begin{tabular}{lcc}
\hline \hline \multicolumn{1}{c}{ Peptide } & $K_{\mathrm{D}}(\mathrm{M})^{a)}$ & Relative affinity \\
\hline hmT-Y & $(2.51 \pm 0.03) \times 10^{-5}$ & 0.024 \\
hmT-NO $2 \mathrm{Y}$ & $(2.34 \pm 0.04) \times 10^{-6}$ & 0.26 \\
hmT-IY & $(6.02 \pm 0.08) \times 10^{-7}$ & 1 \\
hmT-pY & $(3.78 \pm 0.25) \times 10^{-8}$ & 16 \\
\hline
\end{tabular}

a) Values are given as the mean \pm standard error.

by iodination surpassed that by nitration, suggesting that iodination of tyrosine residues may have a stronger influence on cellular functions than nitration. While tyrosine nitration may downregulate phosphotyrosine-dependent signaling, ${ }^{8)}$ it has been suggested that nitration of a tyrosine residue may cause kinase activation. ${ }^{9,15)}$ SFKs have a conserved domain structure consisting of consecutive $\mathrm{SH} 3, \mathrm{SH} 2$, and tyrosine kinase domains. ${ }^{16}$ ) When Tyr 527 is phosphorylated, it interacts with the SH2 domain intramolecularly, leading to inactivation of SFKs (Fig. 2A). ${ }^{1,17)}$ The oncogene v-Src, which lacks Tyr 527, is constitutively active and causes transformation (Fig. 2B). ${ }^{18)}$ Disruption of this interaction may be a mechanism for the abnormal activation of SFKs. Iodination or nitration of Tyr 527 might generate the inactive form of Src kinases as iodotyrosine and nitrotyrosine can bind to the $\mathrm{SH} 2$ domain without being phosphorylated (Table 1); however, the binding affinities of hmT-IY and hmT- $\mathrm{NO}_{2} \mathrm{Y}$ were much lower than that of hmTpY. In addition, iodination and nitration of tyrosine residue caused the peptides to be a poor substrate for PTK (Fig. 1). Thus, if iodination or nitration of Tyr 527 occurs, SFKs could adopt the active conformation (Fig. 2C), leading to upregulation of SFK activity, similarly to v-Src. Mallozzi et al. reported that a nitrotyrosine-containing peptide competed for intramolecular binding and thus upregulated the activity of SFKs. ${ }^{9}$ In this study, hmT-IY exhibited four times higher binding affinity to the Lck SH2 domain, compared with hmT- $\mathrm{NO}_{2} \mathrm{Y}$ (Table 1). This result suggests that iodotyrosine-SH2 domain binding may activate SFKs more efficiently than nitrotyrosine. However, iodinated tyrosine residues from a secondary protein would not readily compete for intramolecular binding with phosphotyrosine 527 unless many tyrosine residues are iodinated, since the binding affinity of hmT-IY was sixteen times 


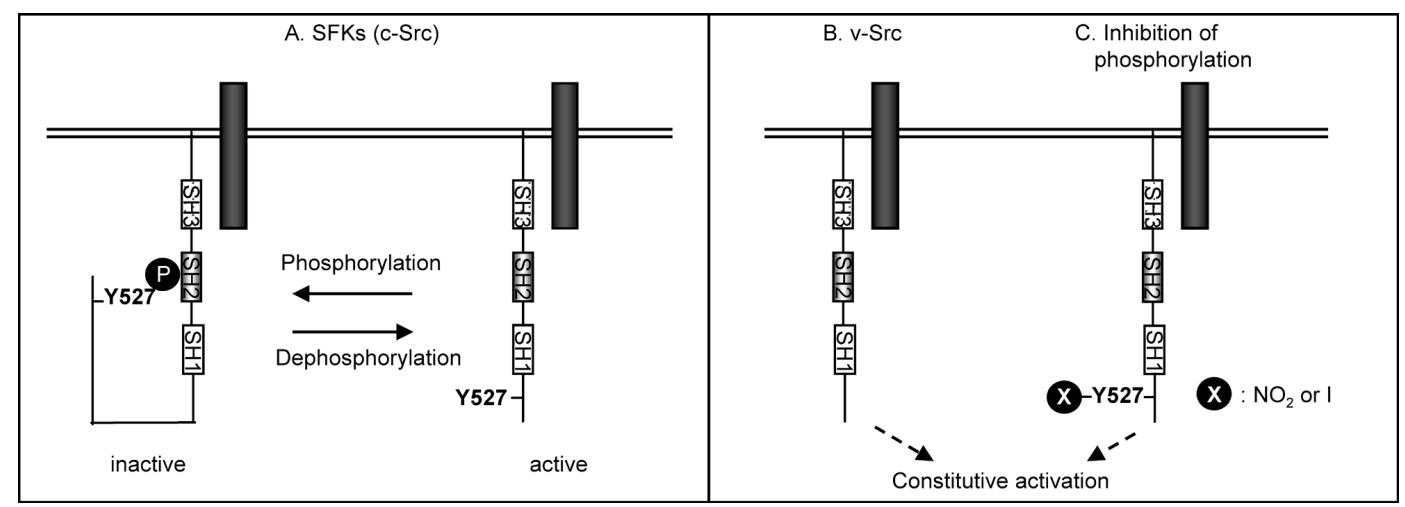

Fig. 2. (A) Model for Regulation of SFKs (c-Src) Activity, (B) The Oncogene v-Src Lacking the Inhibitory Y527 Phosphorylation Site, (C) A Proposed Mechanism for Constitutive Activation of SFKs

(A) Phosphorylation of Y527, located in the tail of c-Src, promotes intramolecularly binding with the SH2 domain and inactivation of kinase activity. (C) Inhibition of Y527 phosphorylation by iodination or nitration prohibits SFKs from adopting the inactive conformation.

lower than that of hmT-pY.

During thyroid hormone biosynthesis, thyroid peroxidase oxidizes iodide to an iodinating species which is then incorporated into tyrosine residues of thyroglobulin. ${ }^{19)}$ In addition to the thyroid, iodide has been reported to bind to tyrosine residues of caseins and other milk proteins in the mammary gland ${ }^{20)}$ and the organification has been demonstrated to correlate with peroxidase activity. ${ }^{21)}$ An in vitro study has also shown that the mammary, salivary, and spleen tissues are capable of iodinating the tyrosine residues of proteins. ${ }^{22)}$ Therefore, it is possible that iodide can be nonspecifically attached to tyrosine residues of proteins or peptides in the extrathyroidal tissues, especially under oxidative stress. This may result in the disruption of cellular function via the modulation of PTK activity. Interestingly, it has been reported that there exist carrier-mediated systems for actively transporting iodide from the brain to the blood, ${ }^{23,24)}$ although their physiological and biological significance remain unknown. In addition, the brain is thought to be prone to oxidative stress, ${ }^{25)}$ and SFKs such as c-Src, Fyn and Yes, are highly expressed in brain and neural tissue. ${ }^{26-28)}$ It is therefore tempting to speculate that the efflux systems remove iodide from the brain to prevent unnecessary iodination.

3-Iodotyrosine of peptides or proteins may undergo further iodination to form 3,5-diiodotyrosine in extrathyroidal tissues. The formation was, in fact, observed in rat milk. ${ }^{29)}$ Although the amount of diiodotyrosine was much lower than that of monoiodotyrosine, ${ }^{29)}$ diiodination of tyrosine residues might inhibit phosphorylation more strongly than monoiodination because of steric hindrance and/or the decrease in the phenolic $\mathrm{p} K_{\mathrm{a}}$ (from 8.2 of 3-iodotyrosine ${ }^{30)}$ to 6.4 of 3,5-diiodotyrosine $\left.^{31}\right)$. For tyrosine nitration, these seem to contribute to the inhibition of tyrosine phosphorylation. ${ }^{32}$ It was also reported that since the shift of the phenolic $\mathrm{p} K_{\mathrm{a}}$ by nitration from $10.1^{30}$ to $7.2^{33)}$ results in the addition of a negative charge at slight alkaline $\mathrm{pH}$, tyrosine nitration probably mimics phosphorylation with respect to the aromatic residue.") Thus, 3,5-diiodotyrosine with the low $\mathrm{p} K_{\mathrm{a}}(6.4)$ could be capable of binding to the SH2 domain. Further studies are needed to clarify the effect of diiodination on the binding to the $\mathrm{SH} 2$ domain and phosphorylation.

In conclusion, we demonstrated that tyrosine halogenation, particularly iodination, causes peptides to be a poor substrate for PTK and that iodotyrosine can bind to the $\mathrm{SH} 2$ domain as a phosphotyrosine mimic. The iodination of tyrosine residues may therefore modulate signal transduction, with the potential to impair cellular function.

\section{REFERENCES}

1) Hubbard SR, Till JH. Protein tyrosine kinase structure and function. Annu. Rev. Biochem., 69, 373-398 (2000).

2) Yarden Y, Sliwkowski MX. Untangling the ErbB signalling network. Nat. Rev. Mol. Cell Biol., 2, 127-137 (2001).

3) Cantley LC, Auger KR, Carpenter C, Duckworth B, Graziani A, Kapeller R, Soltoff S. Oncogenes and signal transduction. Cell, 64, 281-302 (1991).

4) Mohiuddin I, Chai H, Lin PH, Lumsden AB, Yao Q, Chen C. Nitrotyrosine and chlorotyrosine: clinical significance and biological functions in the vascular system. J. Surg. Res., 133, 143-149 (2006).

5) Wu W, Samoszuk MK, Comhair SA, Thomassen MJ, Farver CF, Dweik RA, Kavuru MS, Erzurum SC, Hazen SL. Eosinophils generate brominating oxidants in allergen-induced asthma. J. Clin. Invest., 105, 1455-1463 (2000).

6) Morrison M, Schonbaum GR. Peroxidase-catalyzed halogenation. Annu. Rev. Biochem., 45, 861-888 (1976).

7) Sultana R, Poon HF, Cai J, Pierce WM, Merchant M, Klein JB, Markesbery WR, Butterfield DA. Identification of nitrated proteins in Alzheimer's disease brain using a redox proteomics approach. Neurobiol. Dis., 22, 76-87 (2006).

8) Kong SK, Yim MB, Stadtman ER, Chock PB. Peroxynitrite disables the tyrosine phosphorylation regulatory mechanism: Lymphocytespecific tyrosine kinase fails to phosphorylate nitrated cdc2(6-20) NH2 peptide. Proc. Natl. Acad. Sci. U.S.A., 93, 3377-3382 (1996).

9) Mallozzi C, Di Stasi AM, Minetti M. Nitrotyrosine mimics phosphotyrosine binding to the $\mathrm{SH} 2$ domain of the src family tyrosine kinase lyn. FEBS Lett., 503, 189-195 (2001).

10) Adamson JG, Blaskovich MA, Groenevelt H, Lajoie GA. Simple and convenient synthesis of tert-butyl ethers of Fmoc-serine, Fmocthreonine, and Fmoc-tyrosine. J. Org. Chem., 56, 3447-3449 (1991).

11) Wellings DA, Atherton E. Standard Fmoc protocols. Methods Enzymol., 289, 44-67 (1997).

12) Payne G, Shoelson SE, Gish GD, Pawson T, Walsh CT. Kinetics of p56lck and p60src Src homology 2 domain binding to tyrosinephosphorylated peptides determined by a competition assay or surface plasmon resonance. Proc. Natl. Acad. Sci. U.S.A., 90, 4902-4906 (1993). 
13) Songyang Z, Shoelson SE, Chaudhuri M, Gish G, Pawson T, Haser WG, King F, Roberts T, Ratnofsky S, Lechleider RJ, Neel BG, Birge RB, Fajardo JE, Chou MM, Hanafusa H, Schaffhausen B, Cantley LC. SH2 domains recognize specific phosphopeptide sequences. Cell, 72, 767-778 (1993).

14) Saeki M, Maeda S. p130cas is a cellular target protein for tyrosine nitration induced by peroxynitrite. Neurosci. Res., 33, 325-328 (1999).

15) MacMillan-Crow LA, Greendorfer JS, Vickers SM, Thompson JA. Tyrosine nitration of c-SRC tyrosine kinase in human pancreatic ductal adenocarcinoma. Arch. Biochem. Biophys., 377, 350-356 (2000).

16) Robinson $\mathrm{DR}, \mathrm{Wu} \mathrm{YM}$, Lin SF. The protein tyrosine kinase family of the human genome. Oncogene, 19, 5548-5557 (2000).

17) $\mathrm{Xu} \mathrm{W}$, Harrison SC, Eck MJ. Three-dimensional structure of the tyrosine kinase c-Src. Nature, 385, 595-602 (1997).

18) Jove R, Hanafusa $H$. Cell transformation by the viral src oncogene. Annu. Rev. Cell Biol., 3, 31-56 (1987).

19) Dunn JT, Dunn AD. Update on intrathyroidal iodine metabolism. Thyroid, 11, 407-414 (2001).

20) Shah NM, Eskin BA, Krouse TB, Sparks CE. Iodoprotein formation by rat mammary glands during pregnancy and early postpartum period. Proc. Soc. Exp. Biol. Med., 181, 443-449 (1986).

21) Strum JM. Site of iodination in rat mammary gland. Anat. Rec., 192, 235-244 (1978).

22) Taurog A, Potter GD, Tong W, Chaikoff IL. The formation of I131monoiodotyrosine from I131-iodide by isolated particulate fractions of non-thyroid tissues. Endocrinology, 58, 132-134 (1956).
23) Davson H, Hollingsworth JR. Active transport of 131-I across the blood-brain barrier. J. Physiol., 233, 327-347 (1973).

24) Ahmed N, Van Harreveld A. The iodide space in rabbit brain. $J$. Physiol., 204, 31-50 (1969).

25) Halliwell B. Oxidative stress and neurodegeneration: where are we now? J. Neurochem., 97, 1634-1658 (2006).

26) Maness PF. Nonreceptor protein tyrosine kinases associated with neuronal development. Dev. Neurosci., 14, 257-270 (1992).

27) Pyper JM, Bolen JB. Neuron-specific splicing of C-SRC RNA in human brain. J. Neurosci. Res., 24, 89-96 (1989).

28) Sorge JP, Sorge LK, Maness PF. pp60c-src is expressed in human fetal and adult brain. Am. J. Pathol., 119, 151-157 (1985).

29) Potter GD, Tong W, Chaikoff IL. The metabolism of I 131-labeled iodine, thyroxine, and triiodothyronine in the mammary gland of the lactating rat. J. Biol. Chem., 234, 350-354 (1959).

30) Mayberry WE, Rall JE, Bertoli D. Kinetics of iodination. IV. A comparison of the kinetics of iodination of L-tyrosine and some derivatives. Biochemistry, 4, 2606-2611 (1965).

31) Gemmill CL. The apparent ionization constants of the phenolic hydroxyl groups of thyroxine and related compounds. Arch. Biochem. Biophys., 54, 359-367 (1955).

32) Ischiropoulos H. Biological tyrosine nitration: a pathophysiological function of nitric oxide and reactive oxygen species. Arch. Biochem. Biophys., 356, 1-11 (1998).

33) Sokolovsky M, Riordan JF, Vallee BL. Conversion of 3-nitrotyrosine to 3-aminotyrosine in peptides and proteins. Biochem. Biophys. Res. Commun., 27, 20-25 (1967). 